The subsequent recognition that there

\title{
Signalling bias in new drug discovery: detection, quantification and therapeutic impact
}

\section{Terry Kenakin and Arthur Christopoulos}

Abstract | Agonists of seven-transmembrane receptors, also known as $G$ proteincoupled receptors (GPCRs), do not uniformly activate all cellular signalling pathways linked to a given seven-transmembrane receptor (a phenomenon termed ligand or agonist bias); this discovery has changed how high-throughput screens are designed and how lead compounds are optimized for therapeutic activity. The ability to experimentally detect ligand bias has necessitated the development of methods for quantifying agonist bias in a way that can be used to guide structure-activity studies and the selection of drug candidates. Here, we provide a viewpoint on which methods are appropriate for quantifying bias, based on knowledge of how cellular and intracellular signalling proteins control the conformation of seven-transmembrane receptors. We also discuss possible predictions of how biased molecules may perform in vivo, and what potential therapeutic advantages they may provide.
Measuring the ability of agonist compounds to induce a cellular response (embodied in the pharmacological parameter known as efficacy $)^{1}$ is a key part of the drug discovery process. Historically, it was thought that agonists acting at a given seven-transmembrane receptor - also known as a G-protein coupled receptor (GPCR) - could have different efficacies but each agonist would activate a similar set of signalling proteins. This is because it was thought that all agonists activate receptors by stabilizing a single active conformation of the receptor (known as the active state) and that it was only the strength of the imparted signal that determined the magnitude of the observed efficacy.

A product of this model is the agonist 'potency ratio': that is, the ratio of agonist concentrations that produce $50 \%$ of the maximal response in an in vitro assay. Agonist potency ratios are mathematical expressions of relative agonist activity that are dependent only on the drug-related parameters of affinity and efficacy. Therefore, they are null measurements that allow the quantification system (for example, in a test system) to predict their activity in all other systems (for example, therapeutic systems).

Agonist potency ratios have been highly valuable to the drug discovery process, as drugs are rarely - if ever - developed of the relative activity of agonists in one directly in the therapeutic system. In order for agonist potency ratios to correctly predict the relative agonist activity in a system other than the test system, the paramount assumption is that the link between the initial agonist stimulus at the receptor $(x)$ and the cellular response $(y)$ is monotonic; that is, there can be only one value of $y$ for every value of $x$. When this assumption is not valid, agonist potency ratios that are determined in whole-cell systems become dependent on the test system (such as the particular cell line) and considerably less useful for drug discovery.

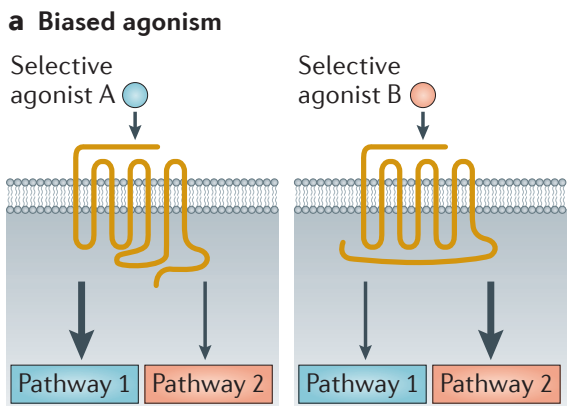

\section{b Biased modulation}


Figure 1 | Trafficking of receptor stimulus by agonists. a| Biased agonism: agonist A produces a biased stimulus for cellular signalling pathway 1 , whereas agonist $B$ produces another receptor conformation that selectively induces bias for cellular signalling pathway 2. b|Biased modulation: an allosteric ligand binds to the receptor, causing a change in the bias of the endogenous agonist. 
consider challenges beyond the in vitro characterization of biased signalling by considering the prediction of biased agonism in vivo.

\section{Measuring agonism in drug discovery}

The concentration-response curve is a timehonoured way of determining the activity of a compound. This tool conveys potency (as a position along the concentration axis) and maximal activity (related to efficacy as the maximal response). These curves can readily be determined in vitro for any defined pharmacological response, such as the production of a receptor-mediated second messenger (for example, cyclic AMP or calcium) or the interaction of the receptor with signalling proteins such as $\beta$-arrestin or G proteins. Through concentrationresponse curves, the relative activity of agonists on different signalling pathways can be compared and biased agonism determined. For a possible bias to be identified at the compound screening stage, it is necessary to separately determine a full concentrationresponse curve (not single-point measures of response) for each signalling pathway so that the pathways can be differentiated. Although this constitutes an early commitment to quantitative analysis during the screening process, the parameters derived from full concentration-response curves can be used to provide quantitative estimates of ligand bias that can be used for the taxonomy of possible candidate molecules during the development process.

As a preface to the discussion of the therapeutic ramifications of biased signalling, it is useful to define what is meant by the term 'bias', as it is a product both of how agonist response is observed and how molecules interact with receptor proteins. It is important to distinguish between these effects as the in vitro agonist response is an experimental artefact that is unique to the systems being studied, whereas only the interaction with receptor proteins is a molecular property of the biased agonist that can be exploited therapeutically in all systems.

\section{Interpretation of the term 'bias'}

Agonist bias was first described in theoretical terms as 'stimulus trafficking', referring to the stabilization of unique conformations of the active state of the receptor ${ }^{2}$, although there were previous reports in the literature ${ }^{11-17}$ of data that were incompatible with models of a single active state of seven-transmembrane receptors. Since its identification, the phenomenon has been given many names, including stimulus trafficking ${ }^{2}$, agonist-directed trafficking of a receptor stimulus ${ }^{18}$, functional dissociation ${ }^{19}$, biased agonism ${ }^{20}$, asymmetrical signalling ${ }^{20}$, biased inhibition ${ }^{21}$, differential engagement ${ }^{22}$, discrete activation of transduction ${ }^{16}$, stimulus bias and functional selectivity ${ }^{23-26}$. The most commonly used terms used to describe this effect are: biased agonism, biased signalling, stimulus bias and functional selectivity.

In general terms, agonist bias can be visualized if two cellular responses (A and B) to a defined agonist are plotted as functions of each other: that is, the amount of signal produced in pathway B is plotted as a function of equal amounts of signal produced in pathway A in response to equimolar concentrations of a given agonist. This results in a 'bias plot ${ }^{5,26}$, a theoretical example of which is shown in FIG. 2. Unless this function is a straight line, the bias plot will indicate that the agonist produces a relatively higher response to one of the pathways compared with the other. Bias plots are useful for graphically expressing the differential activation of two cellular pathways by the same agonist. However, it must be noted that bias plots reflect three different types of agonist-induced changes in cellular signalling (see below), only one of which can be therapeutically targeted.

System bias. System bias reflects the relative efficiency with which different pathways may be coupled to signalling proteins in the cell. Differences in these efficiencies stem from the relative sensitivity of cellular pathways. For example, in rat atria the concentrations of cAMP needed to induce myocardial relaxation are lower than the concentrations needed to induce positive inotropy ${ }^{27}$. System bias will be common for all agonists acting on any specific receptor so it cannot be exploited for therapeutic advantage.

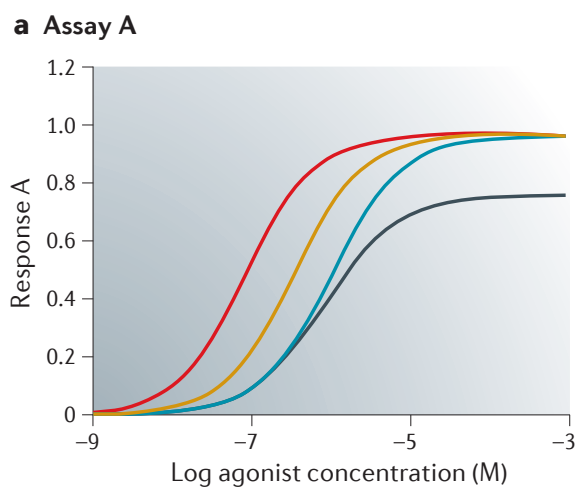

\section{b Assay B}

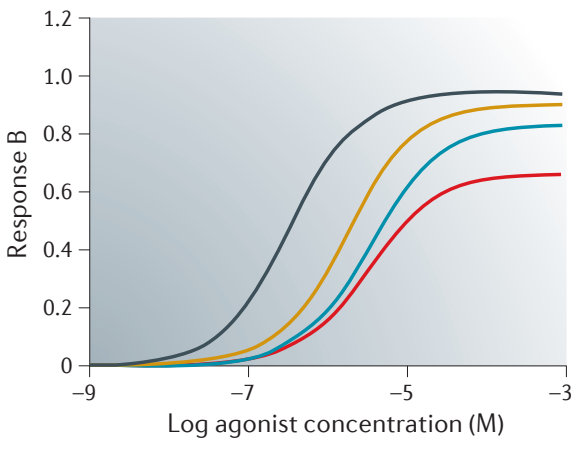

Log agonist concentration (M)

- Agonist $1-$ Agonist $2-$ Agonist $3-$ Agonist 4

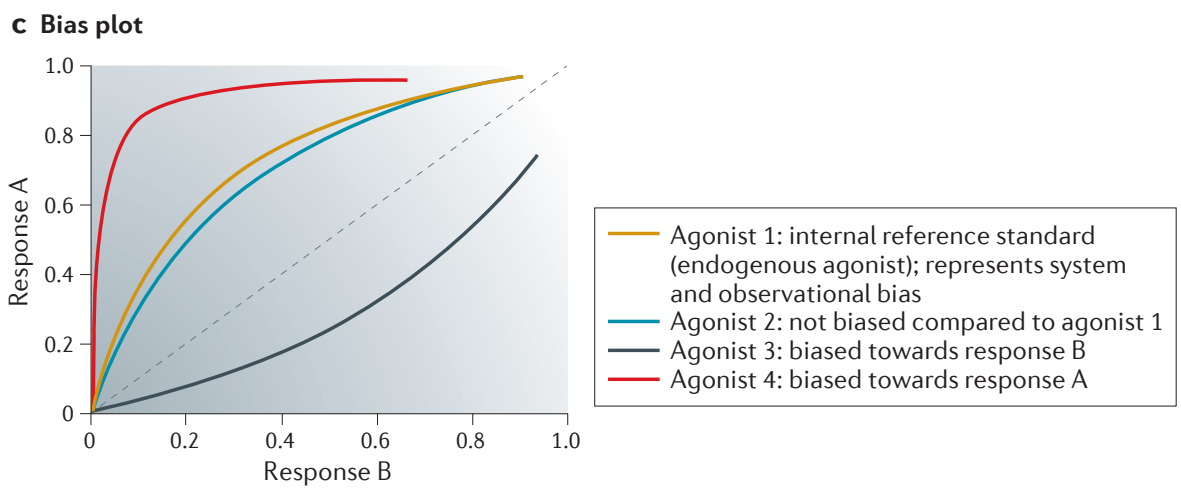

Figure 2 | Bias plots. Responses to four agonists (numbered agonist 1 to 4 ) in two assay systems (assay A (part $\mathbf{a}$ ) and assay B (part b)) are shown. Concentration-response curves in parts $\mathbf{a}$ and $\mathbf{b}$ show the responses to the agonists in each assay. The bias plot (part $\mathbf{c}$ ) shows the response in assay $A$ as a function of the corresponding response in assay B for the four agonists. Agonist 1 is chosen as the reference agonist (any of the four agonists can be used as the reference agonist). It can be seen that agonist 2 produces comparable responses in assay A (as a function of responses in assay B) to agonist 1 . The fact that the lines are curved indicates the degree of system and observational bias in the systems. Agonist 3 produces a considerably lower response in assay A as a function of its responses in assay B, indicating a bias towards response B. Agonist 4 produces considerably greater responses in assay $\mathrm{A}$ for defined responses in assay $\mathrm{B}$, indicating a bias towards response $\mathrm{A}$. 
Observational bias. Another type of bias that is observed when measuring agonism in two different assays is caused by the sensitivity of the various assays that are used to visualize the response of the cell to agonist stimulation; in this article we refer to this as 'observational bias'. Here, the relative sensitivity of each assay determines the relative potency of agonists in those assays, and this fact precludes a direct comparison of these pathways as a measure of bias. For example, the $\beta$-adrenergic receptor agonist isoprenaline has an approximately 500 -fold difference in potency for cAMP production relative to extracellular signal-regulated kinase 1 (ERK1) or ERK2 phosphorylation in the same cell type ${ }^{28}$.

Observational bias is a function of the experimental conditions (for example, buffers, reagents, temperatures as well as temporal and/or kinetic considerations) that are unique to the assays being used to visualize pathway responses and, as with system bias, all agonists will be subject to this effect. As it is an arbitrary product of the sensitivities of the assays used to quantify agonism, it has no bearing on therapeutically useful signalling bias.

Agonist bias. If comparing the effects of a set of agonists on different cellular pathways reveals differences in the activation of signalling pathways that are not due to observational or system bias, they can be caused by ligand bias. Because different intracellular signalling pathways have various sensitivities to agonists, ligand bias must be detected and quantified by comparing the activity of agonists within one assay to a selected standard agonist (in order to remove observational bias and system bias). The relative activity of each agonist in one assay can then be compared to its relative activity in other assays (compared to the same reference agonist in each assay) to yield a relative activity ratio that corrects for system bias and observational bias and can be used across assays to detect true ligand bias between signalling pathways (see the next section).

Biased agonism is associated with the molecular structure of the agonist and so it can be exploited therapeutically. Pharmacological studies using agonists in cell systems provided the initial data supporting the notion that not all agonists stabilize the same active state of a seven-transmembrane receptor to produce a cellular response. This idea has been confirmed through a range of biochemical studies using fluorescence spectroscopy ${ }^{29-36}$, plasmon waveguide resonance spectroscopy $^{37,38}$, bioluminescence resonance energy transfer ${ }^{35,39}$, circular dichroism ${ }^{40}$,

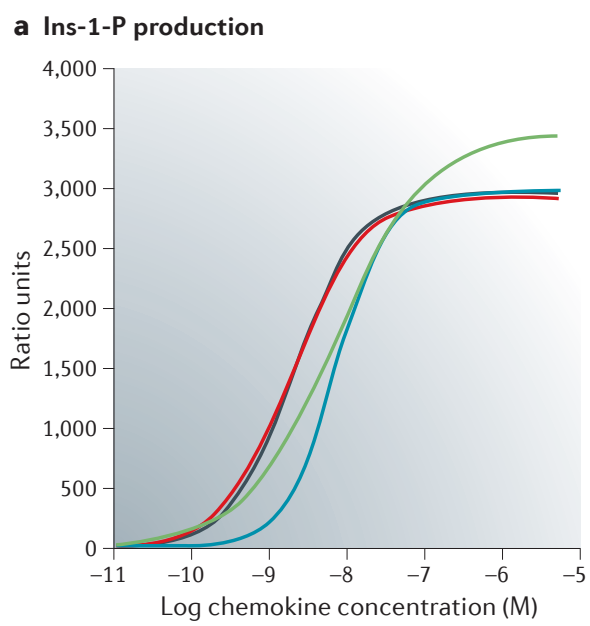

b CCR5 internalization

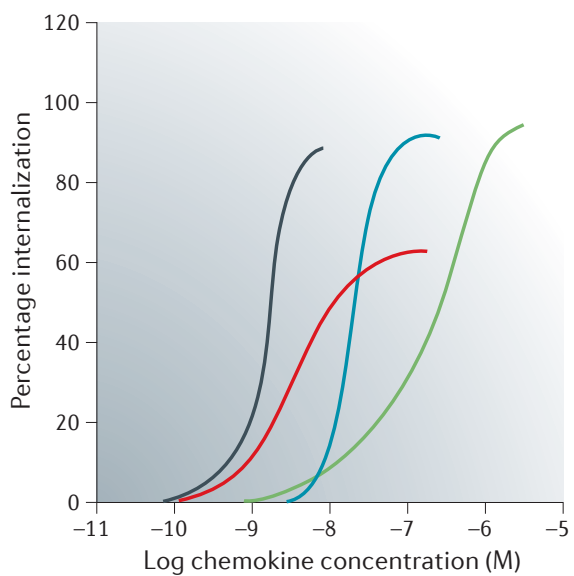

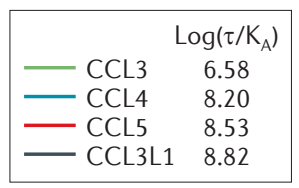

CCR5 internalization

C

Ins-1-P production

Within pathway ratios

Between pathway bias

Within

pathway ratios

\begin{tabular}{ll} 
CCL3 \\
\hline CCL4 \\
\hline CCL5 \\
\hline CCL3L1
\end{tabular}

$\left.\begin{array}{l}1.0 \\ 1.8 \\ 3.3 \\ 5.37\end{array}\right]$

$\begin{array}{ll}1.0 & - \text { CCL3 } \\ 41.7 & \text { CCL4 } \\ 89.1 & \text { CCL5 } \\ 174 & \text { CCL3L }\end{array}$

Figure 3 | Chemokine activation of CCR5. a | Chemokine-mediated activation of chemokine CC motif receptor (CCR5) by different agonists in U373 cells results in increased inositol-1-phosphate (Ins-1-P) production, and the transduction ratios $\left(\log \left(\tau / K_{A}\right)\right.$ values) can be determined. The values in the box below the figure refer to log transduction ratios $\left(\log \left(\tau / K_{A}\right) . \mathbf{b} \mid\right.$ Chemokine-mediated internalization of CCR5 by different agonists in U373 cells; the values in the box below the figure refer to transduction ratios for this process. The respective transduction ratios, expressed as ratios of the value for a reference agonist (in this case, chemokine CC ligand 3 (CCL3)), are shown in the box below the figures. $\mathbf{c | R a t i o s}$ of these numbers are used to calculate the relative bias of the agonists for the two processes. In this case, CCL3L1 is 32.4 times more active than CCL3 at inducing CCR5 internalization when activating CCR5. Data modified, with permission, from REF. 45 @ (2012) American Chemical Society.

X-ray crystallography ${ }^{41}$, site-directed mutagenesis and molecular modelling ${ }^{42}$ as well as ${ }^{19} \mathrm{~F}-\mathrm{NMR}$ spectroscopy ${ }^{43}$. Biased signalling is observed with many ligands that have also been shown to biochemically stabilize different seven-transmembrane receptor conformations ${ }^{3-6}$; this has led to an association between heterogeneous receptor conformations and the phenomenon of biased signalling.

Bias in signalling is caused by the interaction of unique conformations of the active state of the receptor with signalling proteins to produce different relative levels of stimulation to downstream pathways. It can be induced directly by the binding of agonists to the receptor (FIG. 1a) or it can be caused indirectly by the binding of modulators that induce biased signalling via the endogenous agonist (FIG. 1 b).
The term 'biased' is a conditional term and must always be used in the context of another ligand (for example, ligand $x$ is biased towards $\beta$-arrestin signalling in comparison with ligand $y$ ). A standard ligand must be used in assays to detect biased agonism; although the endogenous agonist ligand would be an obvious choice, it must be remembered that endogenous agonists will also exhibit bias because of the existence of system bias. Thus, a synthetic agonist would be biased with respect to the endogenous ligand, but that does not mean the endogenous ligand is unbiased.

There are examples where a given agonist activates one pathway but fails to induce a response in an assay for another pathway; this has been referred to as 'perfect bias'. Caution must be exercised in the use of such a label, as it implies that the agonist does not 
One method proposed to quantify bias is through $\sigma_{\text {lig }}$ values: namely, the ratios of the efficacy of agonists for the activation of a given signalling pathway in a cell. This method assumes that the affinity values for the agonist-receptor complex in the activation of separate signalling pathways are identical ${ }^{61}$. If this assumption is incorrect, this method could lead to substantial errors in the estimation of bias; the magnitude of these errors can be calculated. Thus, as defined in REF. 61 for two agonists designated 'lig' and 'ref':

$$
\sigma_{\text {lig }}=\frac{\tau_{\text {lig }}}{\tau_{\text {ref }}}
$$

Here, $\tau_{\text {lig }}$ and $\tau_{\text {ref }}$ refer to the efficacies of the test and reference agonists, respectively, in the activation of a signalling pathway.

Different signalling pathways are then compared and the difference quantified in the term $\beta_{\text {lig: }}$ :

$$
\beta_{\text {lig }}=\frac{\sigma_{\text {lig }}{ }^{\text {path1 }}-\sigma_{\text {lig }}{ }^{\text {path2 }}}{\sqrt{2}}
$$

Here, the pathways are denoted 'path 1' and 'path 2'.

An equation can be derived (see Supplementary information S7 (box) for the derivation) to demonstrate the relationship between $\beta_{\text {lig }}$ and $\Delta \Delta \log \left(\tau / K_{A}\right)^{45}$ values as estimates of bias:

$$
\left.\sqrt{2} \beta_{\text {lig }}=\Delta \Delta \log \left(\tau / K_{A}\right)_{\text {lig-ref }}+\left(\log \left(K_{\text {A-ref }} / K_{A-\text { lig }}\right)\right)^{\text {path2 }}-\left(\log \left(K_{\mathrm{A}-\text { ref }}\right) K_{\text {A-lig }}\right)\right)^{\text {path1 }}
$$

Here, $\mathrm{K}_{\mathrm{A}-\text { lig }}$ and $\mathrm{K}_{\mathrm{A}-\mathrm{ref}}$ are the $\mathrm{K}_{\mathrm{A}}$ values for the test and reference agonists, respectively. The second and third terms on the right side of the equation refer to any possible differences in the affinity of the agonists when they bind to the seven-transmembrane receptor (also known as $G$ protein-coupled receptor) and subsequently bind to signalling proteins in pathways 1 and 2 . If the affinity of both agonists is identical when pathways 1 and 2 are activated, then these terms will approach zero:

$$
\sqrt{2} \beta_{\text {lig }}=\Delta \Delta \log \left(\tau / K_{A}\right)_{\text {lig-ref }}
$$

If, however, there is an allosterically mediated difference in the functional affinity of either the test or reference agonist as the receptor interacts with the two pathways, then there will be a difference between the estimates made with ratios of transduction coefficients and those made with the $\beta_{\text {lig }}$, with a magnitude equal to that shown in Supplementary information S7 (box):

$$
\Delta \log \text { bias }=\log \left[\frac{\mathrm{K}_{\mathrm{A}-\text { ref }^{\text {path2 }}}}{\mathrm{K}_{\mathrm{A} \text {-ref }}{ }^{\text {path1 }}}\right]+\log \left[\frac{\mathrm{K}_{\mathrm{A} \text {-lig }}{ }^{\text {path1 }}}{\mathrm{K}_{\mathrm{A} \text {-lig }}{ }^{\text {path2 }}}\right]
$$

Although there are theoretical reasons why the use of assumed uniform affinity values may lead to erroneous estimates of bias, and there are examples of situations where a single affinity value cannot be used to fit the operational model to give $\Delta \Delta \log \left(\tau / K_{A}\right)$ or $\sigma_{\text {lig }}$ values ${ }^{48-50}$, there are cases in the literature where $\sigma_{\text {lig }}$ values have been reported and do give a value for bias ${ }^{61}$. The relative effect of signalling proteins on receptor affinity versus efficacy (the type of receptor active state formed) for agonism (see Supplementary information S7 (box)) dictates whether there will be an error in these bias estimates. In situations where this is the case, equation 5 from Supplementary information S7 (box) indicates the size of the error. However, it should also be noted that there are instances where a single binding affinity appears to model the functional affinity of agonists, and in these cases the $\beta_{\text {lig }}$ values will give an accurate estimate of bias.

activate the pathway in all tissues. It cannot be assumed that in vitro experimental conditions will mimic the pathological conditions that determine the effects of a drug when it is administered therapeutically. When apparent 'perfect bias' is encountered, it may be due to the fact that the assay for that pathway is not sensitive enough to detect the effect of the agonist. The use of a more sensitive assay for this pathway might reveal that the agonist can produce a surprisingly powerful effect.

\section{Quantifying bias: survey of methods} It is optimal to characterize and quantify agonist activity in any system in terms of a single parameter, as this will allow the application of statistical methods to assess true differences in agonist activity between drugs. Using potency ( $\mathrm{pEC}_{50}$ values) to characterize and quantify agonist activity is inadequate for agonists that produce different maximal responses. Conversely, using only maximal response to characterize and quantify agonist activity fails to differentiate lus that exceeds the signalling capabilities of the system (thus all agonists yield a uniform maximal response). Therefore, a scale that includes elements of both potency and maximal response is required. Some methods have been described to quantify bias and it is thus timely to compare the various methods available.

Transduction coefficients. As a preface to a discussion of methods used to quantify biased agonism, it is useful to examine the theoretical framework for assessing agonism, and a valuable model in this regard is the Black-Leff operational model ${ }^{44}$ for quantifying drug responses (see Supplementary information S1 (box)). Within this model, agonism can be quantified in a systemindependent parameter that considers both the operational affinity and efficacy of agonists in the form of a 'transduction coefficient': $\tau / \mathrm{K}_{\mathrm{A}}{ }^{45}$; the term $\tau$ incorporates agonist efficacy, receptor density and coupling within the system, and the dissociation constant $\mathrm{K}_{\mathrm{A}}$ is the reciprocal of the conditional affinity of the agonist in the functional system.

For full agonists, a given potency can result from infinite combinations of efficacies and affinities. Ratios of $\tau / K_{A}$ values are identifiable as a unique value associated with a given agonist potency as they are essentially the reciprocal of the $\mathrm{EC}_{50}$ value produced by a full agonist (that is, a single value). It has been shown experimentally that transduction coefficients remain constant over large changes in receptor density ${ }^{45}$; this is a required property for a scale that is used to determine agonist bias, as it would be expected that different tissues would have varying receptor densities on the cell surface.

It should be noted that the $\mathrm{K}_{\mathrm{A}}$ parameter in this calculation is a measure of the conditional affinity and not the affinity of the ligand for the bare receptor (that is, the receptor uncoupled from intracellular signalling proteins). As the receptor functions by coupling to signalling proteins, the affinity of the agonist for the bare receptor is not relevant to the functional activity of the ligand in a cellular system (the bare receptor produces no functional response). In the scheme shown below, the agonist $\mathrm{A}$ thus promotes a change in the receptor from the $\mathrm{R}$ to the $\mathrm{R}^{\star}$ state:

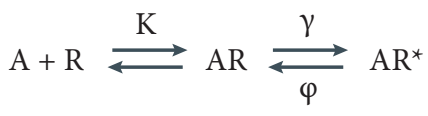

The receptor 'isomerizes' (that is, it becomes another thermodynamic protein species through ligand binding) from the $\mathrm{R}$ 


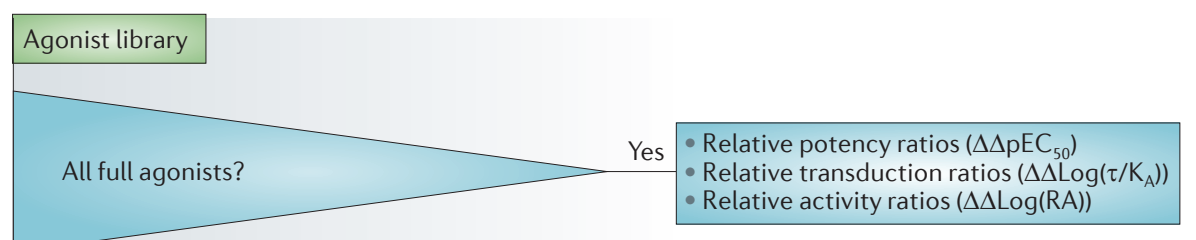

relative activity ratios of each agonist across different pathways (as $\Delta \Delta \log \left(\tau / \mathrm{K}_{\mathrm{A}}\right)$ values) can be determined as measures of agonist bias. An example of this procedure is shown in FIG. 3.

No

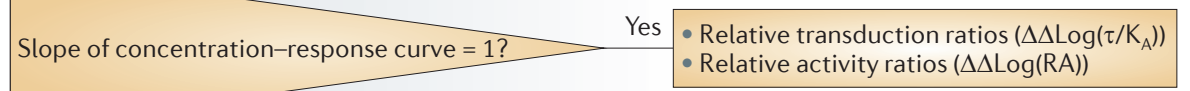

No

- Relative transduction ratios $\left(\Delta \Delta \log \left(\tau / K_{A}\right)\right)$

Figure 4 | Logistical scheme for quantifying signalling bias for agonists in a system-independent manner. The scheme illustrated will be system-independent only for defined in vitro systems that measure a molecular allosteric vector (direct interaction between a ligand, receptor and signalling molecule). Bias estimates may become cell-type-dependent for biased agonists in whole-cell assays or assays in which other signalling components of the cell contribute to the observed response. $\mathrm{K}_{\mathrm{A}}$, dissociation constant; $\mathrm{pEC} \mathrm{C}_{50}$, negative logarithm of the $\mathrm{EC}_{50}$; RA, relative activity.

to the $\mathrm{R}^{\star}$ state through the efficacy-related processes $\gamma$ and $\phi$ (that is, the conformational state of the receptor is not confined to the agonist-receptor (AR) complex $)^{46,47}$. The observed affinity will be an amalgam value, $K_{A}$, of the magnitude:

$$
\mathrm{K}_{\mathrm{A}}=\frac{\mathrm{K}}{1+\frac{\gamma}{\varphi}}
$$

The application of the Black-Leff operational model to agonism has been described in the literature ${ }^{48-50}$ to show the differences in the functional affinity of agonists when they activate separate signalling pathways; specifically, the operational model cannot accommodate data for partial agonists with divergent $\mathrm{EC}_{50}$ values by using a single $\mathrm{K}_{\mathrm{A}}$ value. These data underscore the finding that there are examples showing that a single estimate of affinity fails to adequately describe the functional agonist activation of multiple signalling pathways. These examples are described in Supplementary information $\underline{\text { S2 }}$ (box).

Seven-transmembrane receptor agonism is an allosteric process defined by the facilitation of receptor-protein interactions with signalling proteins (such as $\mathrm{G}$ proteins and $\beta$-arrestin) following the binding of agonist molecules. This means that the affinity of ligands for seven-transmembrane receptors may depend on the interaction of that receptor protein with other signalling proteins in the cell. Thus, as in all allosteric systems, the affinity of the agonist is conditional on the properties and concentration of the signalling protein. The agonist-receptor-transducer complex, and not just the agonist-receptor complex, is therefore the minimal biological unit needed to produce a cellular response $\mathrm{e}^{51}$. This idea is supported by structural studies of the $\beta_{2}$-adrenergic receptor showing changes in the three-dimensional structure of the receptor with either a $G$ protein ${ }^{52}$ or a nanobody that mimics $\mathrm{G}$ protein binding ${ }^{53}$; such structural changes would suggest a concomitant alteration in agonist affinity (Supplementary information S3 (box)).

In general, it is our view that the $\mathrm{K}_{\mathrm{A}}$ value in the operational model should not be confused with independently determined $\mathrm{K}_{\mathrm{A}}$ values from binding assays as they are intrinsically different. The idea that agonist affinity may be conditional and subject to the nature of the signalling protein that is associated with different signalling pathways argues against the use of a single biochemical estimate of agonist affinity derived from a single binding study for use in the calculation of bias (as discussed below).

The transduction coefficient scale reduces the measurement of agonism to a single number and thus enables the statistical analysis of differences. The key for the correct use of this scale is as follows: first, compare values for a set of agonists to each other within a given pathway; second, express $\log \left(\tau / \mathrm{K}_{\mathrm{A}}\right)$ ratios (the relative power of each agonist to induce a response) as ratios to a defined reference agonist (that is, as $\left.\Delta \log \left(\tau / K_{A}\right)\right)$ as this will cancel the effects of system and observational bias. Finally,
Relative activity values. Another parameter that has been used to quantify biased agonism is the 'relative activity' scale $e^{54-56}$. This scale uses a ratio of the maximal response to the $\mathrm{EC}_{50}$ value for an agonist (log (relative activity; RA $\left.)=\log \left(\max / \mathrm{EC}_{50}\right)\right)$; this takes into account the agonist potency and the maximal response produced by an agonist in a given system. For concentration-response curves with slopes that are not significantly different from unity, it can be shown that the relative activity value reduces to transduction coefficient values ${ }^{57}$. The $\log (\mathrm{RA})$ scale has the advantage of being simple to calculate in cases where fitting the data to the Black-Leff operational model is problematic (see Supplementary information S4 (box)), but it requires that the slope of the concentration-response curves is not significantly different from unity. The comparison of $\log (\mathrm{RA})$ values thus offers another method of quantifying agonist bias ${ }^{58}$.

Comparison of agonist equiactive concentrations. Another method used to quantify agonism, which was originally used to estimate the relative affinity of a partial agonist ${ }^{59,60}$, compares equiactive concentrations of a full and partial agonist to calculate the ratios of agonist efficacy and agonist affinity for each agonist $\left(\tau / \mathrm{K}_{\mathrm{A}}\right)$. When applied to a single signalling pathway, this furnishes ratios of transduction coefficients (Supplementary information S5 (box)). As with the relative activity scale, this method is only valid for functional systems in which the concentration-response curves have slopes that are not significantly different from unity.

$\beta_{\text {lig }}$ and $\sigma_{\text {lig }}$ values. Another method that has been proposed to quantify agonist bias calculates a term designated as $\beta_{\text {lig }}{ }^{61}$. This method is similar to the transduction coefficient method as it uses the Black-Leff operational model to estimate the efficacy of the agonist ( $\tau$ values). However, it differs from the transduction coefficient scale by assuming that a single estimate of $\mathrm{K}_{\mathrm{A}}$ for the receptor (obtained from biochemical binding studies) should be used to fit the data to the operational models. This therefore means that the dissociation constant $\left(\mathrm{K}_{\mathrm{A}}\right)$ will effectively be the same for each pathway at which biased agonism is calculated. For the reasons highlighted above, there is 
little rationale for assuming that the functional affinity of an agonist for its receptor will be the same when that receptor interacts with different cellular signalling proteins. If the affinity of the agonist does change when different signalling proteins are coupled to the receptor, the use of an independent single estimate of agonist affinity for the calculation of $\beta_{\text {lig }}$ values may introduce an error into the calculation of bias. The size of this error is dependent on the magnitude of the difference in the operational affinity of the agonist for the receptor, as the receptor interacts with different pathways (Supplementary information S2 (box)), and can be unpredictable (see Supplementary information S6 (box) for further details).

This raises the possibility that the affinity of certain agonists may change only slightly in the presence of different guest signalling molecules on the receptor, making the error term for bias of these specific molecules relatively small (see BOX 1 and Supplementary information S7 (box)). Depending on the differences in receptor affinity with various signalling pathways, the $\sigma_{\text {lig }}$ method will produce estimations of bias that are very similar to the transduction coefficient method for some agonists and very different for others.

\section{Preferred methods to quantify ligand bias?}

In general, we believe that the theoretically most sound method of quantifying ligand bias in vitro is through ratios of transduction coefficients $\left(\Delta \Delta \log \left(\tau / \mathrm{K}_{\mathrm{A}}\right)\right)$ or ratios of changes in relative activity $(\Delta \Delta \log (\mathrm{RA})$ values for agonists that produce concentration-response relationships with slopes that are not significantly different from unity), certainly in cases where it can be shown that the application of a uniform affinity value cannot mathematically fit the concentration-response curves for multiple pathways for some agonists (see Supplementary information S2 (box)). The use of $\sigma_{\text {lig }}$ and $\beta_{\text {lig }}$ values will provide useful estimates of a High 7TMR density

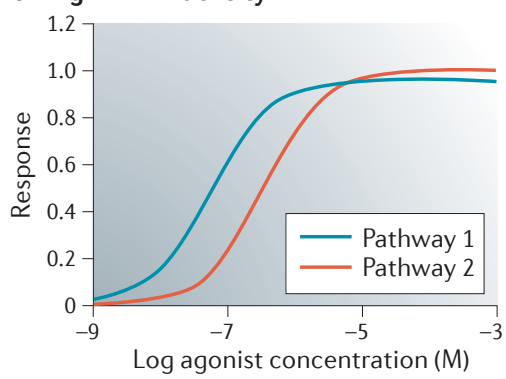

b Low 7TMR density

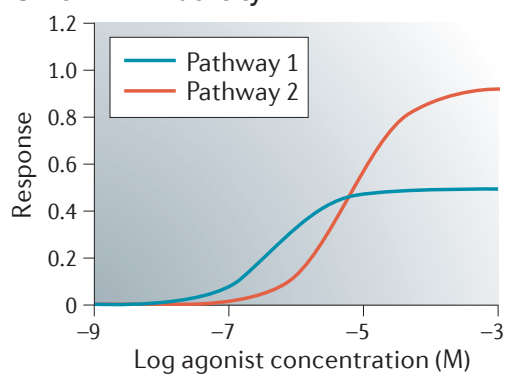

c

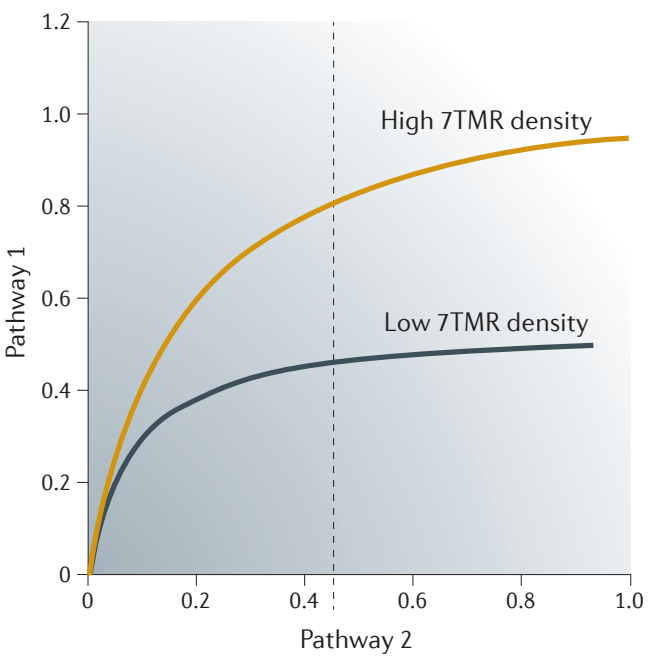

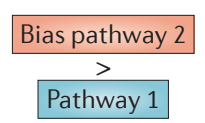

Figure 5 | Interplay of tissue sensitivity and ligand bias. Panel a shows the concentration-response curves of the agonist for the two pathways in the sensitive tissue. Panel $\mathbf{b}$ shows the concentrationresponse curves of the agonist for the two pathways in the tissue with low sensitivity. Panel c shows that an agonist with a defined bias for pathway 1 over pathway 2 (relative log(transduction ratio; $\left.\Delta \log \left(\tau / K_{A}\right)_{(1-2)}=0.824\right)$ can show variable effective bias in vivo in tissues with differing receptor density. In this simulation, in a sensitive tissue with a high receptor density the agonist shows a clear bias throughout the full concentration range for the response, as indicated by the orange hyperbolic line on the left of the line of equivalence (dotted straight line). However, in a tissue of lower sensitivity (black hyperbolic line), the hyperbolic asymptotic value at ordinate $=0.45$ shows that over a low concentration range the effect of the agonist is biased for pathway 1 over pathway 2, but at higher agonist concentrations this changes to a preference for pathway 2 over pathway 1 . Parameters for agonist: high-sensitivity tissue: $\log \left(\tau / K_{A}\right)_{1}=7.3 ; \log \left(\tau / K_{A}\right)_{2}=6.48 ; \Delta \log \left(\tau / K_{A}\right)_{(1-2)}=0.824$. Low-sensitivity tissue: $\log \left(\tau / K_{A}\right)_{1}=5.0 ; \log \left(\tau / K_{A}\right)_{2}=4.18 ; \Delta \log \left(\tau / K_{A(1-2)}\right)=0.824$. 7TMR, seven-transmembrane receptor.

agonist bias in cases where the affinity of the receptor for the ligand has been shown to remain constant in different signalling pathways. In assays in which agonists have the same observed maximal response (that is, full agonists), the use of $\Delta \mathrm{pEC}_{50}$ values to determine bias is sufficient. Agonist equiactive concentrations can also be used to compare full and partial agonists in order to yield ratios of transduction coefficients. A general scheme for comparing various types of agonists is given in FIG. 4.

\section{Translating bias to in vivo effects}

Methods such as those discussed above can be used to derive estimates of ligand bias factors for a defined set of in vitro experimental conditions, but agonists will probably encounter a range of tissues with varying sensitivity to agonists and different receptor densities in vivo. It is expected that differences in receptor density, the relative stoichiometry of signalling elements and receptor coupling efficiencies will lead to quantitative differences in cellular signals for different agonists. For example, in Chinese hamster ovary $(\mathrm{CHO})$ cells containing high levels of expression of $\beta_{3}$-adrenergic receptors the dominant signalling pathway is cAMP, whereas at low levels of expression the signalling pathway changes to mitogen-activated protein kinase 14 (MAPK14; also known as p38 MAPK); this change leads to substantial differences in the biased signalling of the ligands CL316243 ( $R, R)-5$ - [2-[[2(3-chlorophenyl)-2-hydroxyethyl]-amino]propyl]1,3-benzodioxole-2,2-decarboxyl ate) and SR59230A (3-(2-ethylphenoxy)-1$[(1, S)$-1,2,3,4-tetrahydronapth-1-ylamino]$2 S$-2-propanol oxalate $)^{62}$.

The impact of tissue sensitivity (or receptor density) on agonist bias is shown in FIG. 5. Specifically, in a highly sensitive tissue an agonist with a defined bias for pathway 1 over pathway 2 (determined as a transduction coefficient defined by $\Delta \log \left(\tau / \mathrm{K}_{\mathrm{A}}\right)_{(1-2)}$ $=0.824$ ) induces a greater response in pathway 1 over a broad concentration range. By contrast, in a tissue with lower sensitivity to agonists, this same agonist (with the same ligand bias) induces a greater response in pathway 1 (over pathway 2) at low concentration ranges but a greater response in pathway 2 (over pathway 1 ) at higher concentration ranges.

The unpredictable bias of agonists in tissues of varying sensitivity highlights that the magnitude of agonist efficacy also has a role in the interaction between efficacy and affinity. That is, there can be two agonists 
with an identical bias but differing strengths of efficacy, and these agonists may behave differently in vivo. These types of effects make the in vivo prediction of biased agonist profiles difficult.

At present, owing to the lack of methods that allow the stable prediction of biased agonism in vivo, we propose an operational strategy whereby exemplar molecules of known bias and efficacy (that have been quantified using in vitro methods) are tested in vivo to try to link in vitro estimates of agonist bias to phenotype profiles that are observed in vivo. Agonist bias can be determined $^{63}$ using a mathematical formalism (termed $\mathrm{B}_{\mathrm{a}}$ ) that describes biased agonist signalling probabilities for tissues with a varying range of sensitivities; REF. 63 highlights the variability between in vitro and in vivo comparisons of bias.

\section{The impact of bias on drug discovery}

Ligand-specific stabilization of seventransmembrane receptor conformation has influenced drug discovery in two major areas. First, because biased agonists do not produce monotonic stimulus-response coupling, agonist potency ratios determined in whole cells can be shown to be dependent on the cell type and assay type (FIG. 6). Once the stimulus progresses beyond the allosteric vector and interacts with elements of the cytosol (such as ERK1 or ERK2 phosphorylation and calcium release from intracellular stores), then the cell controls the relative contributions from the various pathways to the overall cellular response. This means that different agonists may stabilize different conformations of a seven-transmembrane receptor to differentially interact with celldependent pools of signalling proteins.

This, in turn, predicts that biased agonists will have variations in relative potency ratios in different cell types and in different assay formats. This has been shown with the expression of calcitonin receptor agonists in different host cells ${ }^{64}$ or with the co-expression of different levels of $\mathrm{G}$ proteins in the same cell line ${ }^{65}$, and has also been observed when whole-cell agonist potency ratios are determined using different assay formats ${ }^{66}$. Such data suggest that whole-cell agonist potency ratios, at least for biased agonists, should be considered suspect as predictors of relative activity in other systems. Conversely, because biased agonists will probably produce variations in whole-cell potency ratios that are dependent on the assay format and cell type, the screening of agonists in different cells using label-free technology could provide a useful and rapid method of detecting

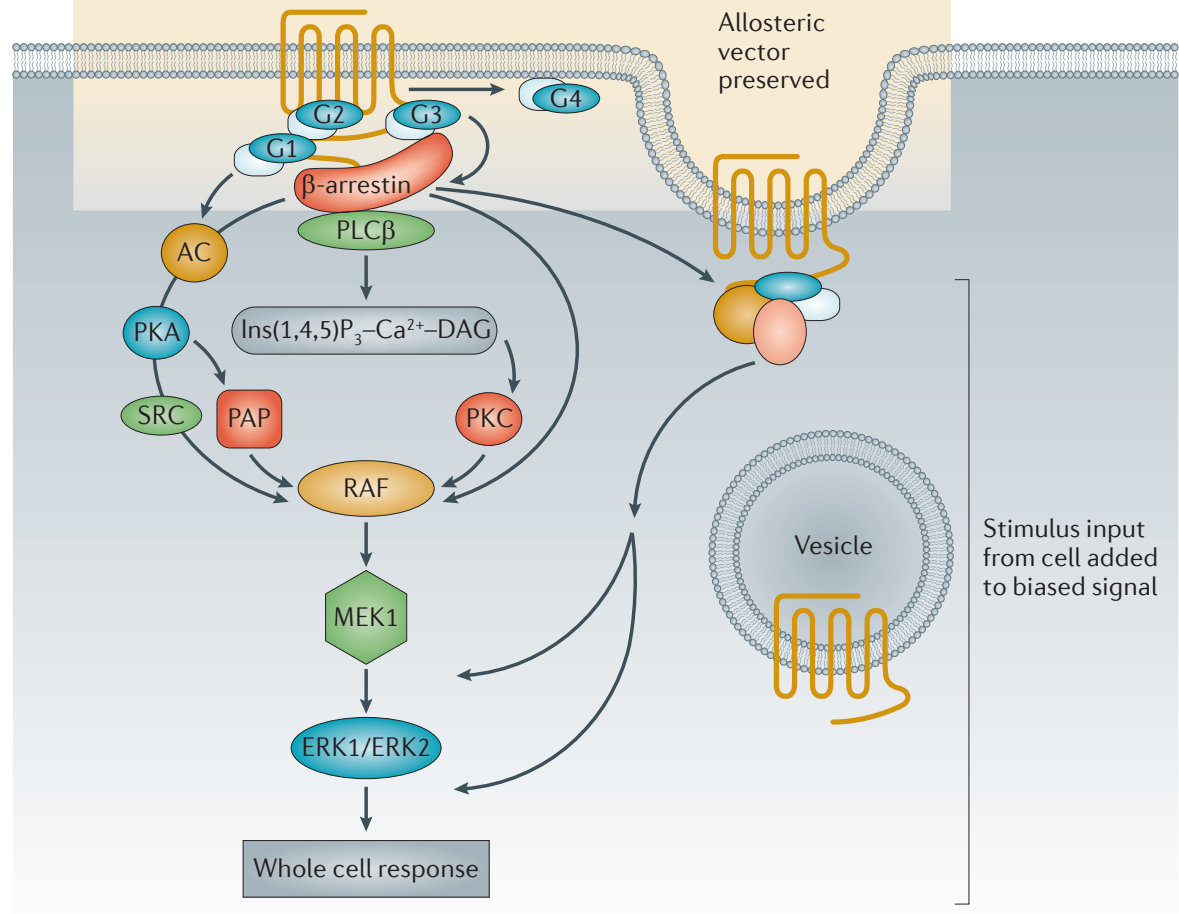

Figure $6 \mid$ The interaction of the receptor and allosteric vector with cellular signalling components. The stabilization of unique receptor conformations (leading to biased signalling) is determined by the molecular properties of the agonist, receptor and signalling proteins (in this case the different $\mathrm{G}$ proteins $\mathrm{G}_{1}, \mathrm{G}_{2}, \mathrm{G}_{3}$ and $\beta$-arrestin) at the level of the ternary complex; this is defined as the allosteric vector and shown in the orange rectangle. The strength of the signal imparted to the cell by the agonist is determined by the molecular parameters governing the direct activation of the receptor (efficacy, $\tau$ ) and the allosteric effect of the ligand on endogenous receptor affinity (and efficacy ( $\alpha$ and $\beta$, respectively, in the model described in Supplementary information S3 (box)). However, this signal can then interact with other pathways in the cell and the total cellular response thus becomes the result of an amalgam of stimuli. Under these latter circumstances, the relative stoichiometry of the signalling components in the cell can change the nature of the ultimate cellular response, making whole-cell responses cell type-dependent. AC, adenylyl cyclase; DAG, diacylglycerol; ERK1, extracellular signal-regulated kinase $1 ; \operatorname{lns}(1,4,5) \mathrm{P}_{3}$, inositol-1,4,5-trisphosphate; MEK1, MAPK (mitogen-activated protein kinase)/ERK kinase 1; PAP, poly(A) polymerase; PKA, protein kinase A; PLC $\beta$, phospholipase $C \beta$.

biased agonists ${ }^{66}$. However, efficacy within the allosteric vector will be cell type-independent (see Supplementary information S6 (box)).

Second, biased agonism may also control the quality of the efficacy in seven-transmembrane receptor signalling. Specifically, agonists acting on pleiotropically coupled receptors have the potential to cause bias towards some signalling pathways and not others; this, in turn, will affect the overall make-up of the signal passed on to the tissue. For example, parathyroid hormone activates $G$ proteins and causes the receptor to associate with $\beta$-arrestin, whereas analogues of the hormone can separate these pathways. The parathyroid hormone-related protein (PTHRP) analogue [Trp ${ }^{1}$ PTHRP-(1-36) causes the receptor to preferentially couple to G proteins, whereas PTH-1A ([D-Trp $\left.{ }^{12}, \mathrm{Tyr}^{34}\right]$ PTH-(7-34)) causes the receptor to preferentially couple to $\beta$-arrestin ${ }^{67}$. Similarly, the Substance P analogue SpD ([D-Arg ${ }^{1}, \mathrm{D}-$ Phe $^{5}, \mathrm{D}^{-} \operatorname{Tr}^{7,9}$, Leu $\left.^{11}\right]$ Substance P) selectively induces $G$ protein-dependent signalling, whereas bombesin induces $G$ proteinindependent $\beta$-arrestin activity ${ }^{68}$. This type of selectivity imposes a further requirement on target validation in drug discovery: that is, determining which aspect of target signalling is therapeutically relevant.

In order to optimally predict the therapeutic effects of biased agonists, it is necessary to determine the effects of the various agonists on different signalling pathways. This can be done by carrying out sequential screening 


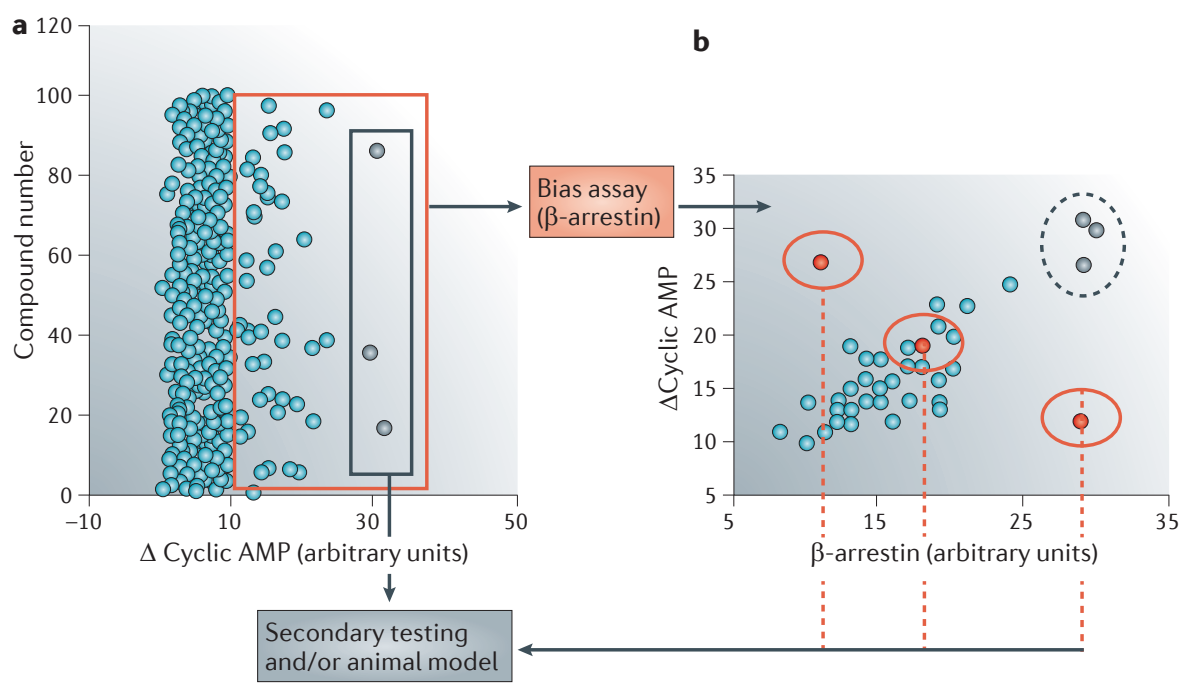

Figure $7 \mid$ The impact of signalling bias on drug screening. a | Historically, it was assumed that all agonists lead to the formation of an identical receptor active state. Under this assumption, screening of a set of agonists (each represented by blue circles) selected the most active molecules in a given assay: for example, cyclic AMP accumulation. These molecules were then tested in secondary models. b|Now that it is known that biased agonism exists (that is, efficacy has a quality as well as magnitude), a larger sample of active molecules (encompassed by the red rectangle) from the first screen can be tested in an assay for another signalling pathway (for example, $\beta$-arrestin) to determine the relative activity of exemplar molecules (grey and red circles) on the two pathways. Under these circumstances, several molecules with differing biases can be tested in the model to determine possibly different phenotypes of activity in vivo.

of molecules in different assays (FIG. 7). Once exemplar molecules (that is, molecules that are biased for various pathways) have been identified, they can be tested in more complex models (for example, whole animal models of disease) to determine activity phenotypes that may allow more accurate predictions of therapeutic value. In addition, therapeutic linkages of bias profiles have been made using gene knockout animals (for example, knockout animals for $\beta$-arrestin 1 (REF. 69), $\beta$-arrestin 2 (REF. 7) and p90 ribosomal S6 kinase $^{48}$ ). Quantification of the bias observed with these exemplar molecules should then become a crucial part of the lead optimization phase of the drug discovery process.
Allosteric ligands and biased signalling

It is now well established that seventransmembrane receptors can possess allosteric binding sites that are recognized by small molecules, peptides or proteins ${ }^{70-74}$. Allosteric ligands promote distinct conformational states that modulate the interactive properties of the receptor towards other ligands and/or intracellular signalling proteins ${ }^{75,76}$. In addition, there are several examples of allosteric ligands that can directly alter the basal signalling state of the receptor, thus acting as allosteric agonists.

There are also examples of direct allosteric agonists that promote a different signalling profile at a given receptor compared to the cognate orthosteric agonist ${ }^{77-79}$. For example, in addition to allosterically potentiating the function of the orthosteric agonist $R$-PIA at the adenosine $\mathrm{A}_{1}$ receptor, the 2-amino-3-benzylthiophene VCP520 activates the receptor in its own right to initiate signalling pathways that are different from those activated by the orthosteric agonist $^{79}$ (FIG. 8a). Another example is the allosteric tetrapeptide ASLW (Ala-Ser-LeuTrp), which promotes substantial activation of CXC chemokine receptor 4 (CXCR4) without inducing internalization, whereas the cognate agonist chemokine CXC ligand 12 (CXCL12) mediates both processes ${ }^{78}$.

When investigating the effects of allosteric modulators in drug screening programmes, the interaction of the endogenous agonist must be considered, as endogenous agonists bind to sites that are separate from the allosteric modulator. Under these circumstances, allosteric modulators have the potential to change the coupling preferences of any co-bound

\section{Glossary}

\section{$\left.{ }^{35} \mathrm{~S}\right] \mathrm{GTP} \gamma \mathrm{S}$}

${ }^{35}$ S-labelled GTP; a non-hydrolysable G protein-activating analogue of GTP that is used to measure interactions between seven-transmembrane receptors (also known as GPCRs) and G proteins.

\section{Allosteric binding site}

The site on a seven-transmembrane receptor protein (also known as GPCR) to which modulators bind to affect the subsequent binding and effect of another ligand that interacts with the receptor; this ligand is usually the endogenous agonist binding to its cognate (that is, orthosteric) binding site.

\section{Conditional affinity}

The measured affinity of a ligand for a seven-transmembrane receptor (also known as GPCR) when the receptor is bound to an allosteric guest molecule (such as a $\mathrm{G}$ protein or $\beta$-arrestin). The conditional affinity of the ligand for the receptor will vary with the concentration and type of the guest molecule that is co-bound.

\section{Efficacy}

The property of a molecule that causes a change in the behaviour of a seven-transmembrane receptor (also known as GPCR) towards the cell when the molecule is bound to the receptor.

$\mathrm{EC}_{50}$

The concentration of an agonist that produces $50 \%$ of the maximal response to the agonist for a defined signalling response pathway.

Full agonists

Agonists that induce the maximum obtainable response that can be produced by a signalling system.

\section{Operational affinity}

Also referred to as functional affinity. The apparent equilibrium dissociation constant of the agonist-receptor complex, as determined by fitting the Black-Leff operational model to agonist concentration-response curves.

\section{Orthosteric agonist}

An agonist that binds to the same binding site on the seven-transmembrane receptor protein (also known as GPCR) as the endogenous agonist (that is, the orthosteric binding site).

$\mathrm{pEC}_{50}$

Negative logarithm of the $\mathrm{EC}_{50}$ (the concentration of an agonist that produces $50 \%$ of the maximal response to the agonist for a defined signalling response pathway)

\section{Receptor coupling efficiencies}

A term that describes the degree of seven-transmembrane receptor (also known as GPCR) occupancy by an agonist; receptor coupling efficiency relates to the resulting cellular response. A low receptor occupancy that yields a large cellular response constitutes a high coupling efficiency. 


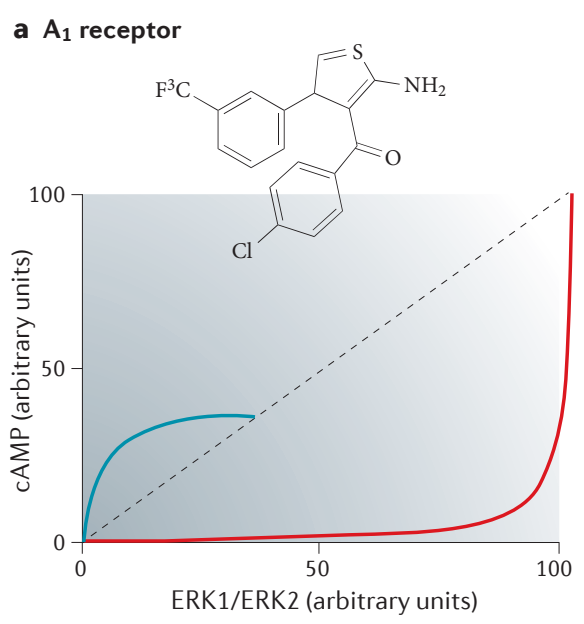

ERK1/ERK2 (arbitrary units)

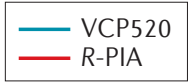

\section{b $M_{2}$ receptor}
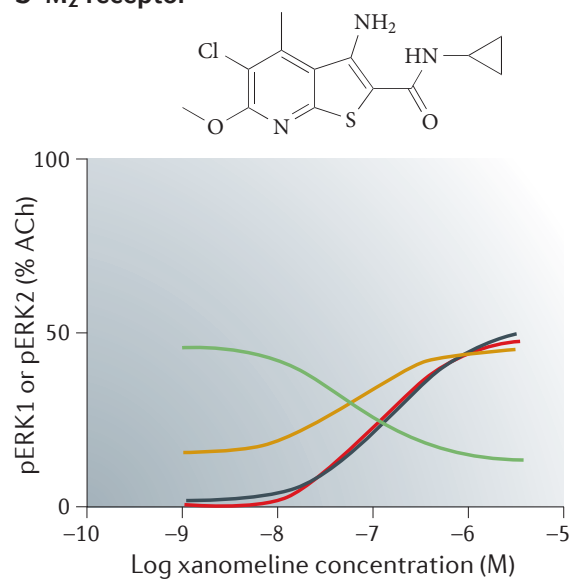

[LY2033298] $(\mu \mathrm{M})$

$\begin{array}{ll}-0 & -1.0 \\ -0.1 & -10\end{array}$

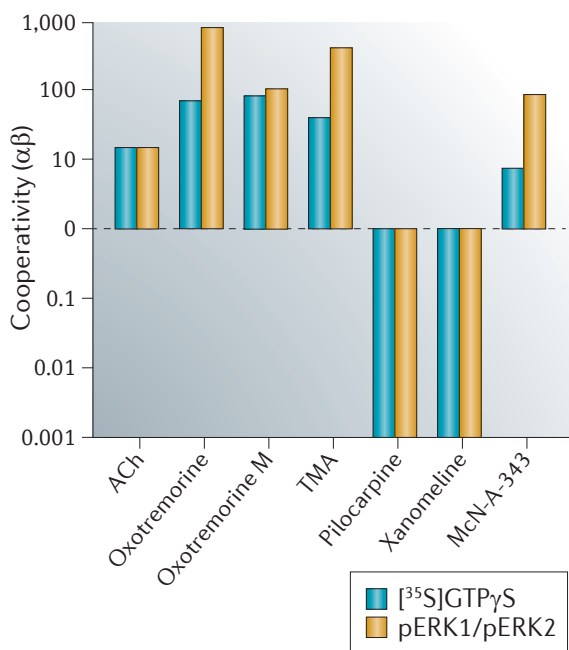

Figure 8 | Biased allosteric agonism and modulation. a| The bias plot shows the signalling preferences of the allosteric agonist VCP520 and orthosteric agonist R-PIA for the inhibition of forskolin-stimulated cyclic AMP or stimulation of extracellular signal-regulated kinase 1 (ERK1) or ERK2 phosphorylation via the adenosine $A_{1}$ receptor. Data modified, with permission, from REF. 79 @ (2012) American Chemical Society. b| The allosteric modulator LY2033298 changes the signalling properties of the $M_{2}$ muscarinic receptor in an orthosteric ligand (xanomeline)- and pathwaydependent manner. The left panel shows the effect of LY2033298 on the concentration-response relationship produced by the orthosteric agonist xanomeline on ERK1 or ERK2 phosphorylation. The right panel shows the cooperativity estimates ( $\alpha \beta$ values as measures of the overall degree of allosteric potentiation or inhibition) for the interaction between LY2033298 and the indicated orthosteric agonist across two different pathways: $\left[{ }^{35}\right.$ S]GTP $\gamma S$ binding or ERK1 or ERK2 phosphorylation. Data modified, with permission from REF. 115 (C) (2012) American Society for Pharmacology and Experimental Therapeutics. ACh, acetylcholine; pERK, phosphorylated ERK. orthosteric endogenous agonists, leading to the phenomena of biased antagonism or potentiation. This has been shown for prostaglandin D2 receptor 2 (PTGDR2; also known as CRTH2) ${ }^{80}$, metabotropic glutamate receptors ${ }^{81}$, neurokinin 2 (also known as substance $\mathrm{K}$ ) receptors $^{82}$, muscarinic $\mathrm{M}_{1}$ (REF. 83) and $\mathrm{M}_{3}$ receptors ${ }^{84}$, prostaglandin $\mathrm{F}_{2} \alpha$ receptors ${ }^{85}$ and the calcium-sensing receptor $^{86}$. For example, when acting on PTGDR2 the allosteric modulator 1-(4-ethoxyphenyl)5-methoxy-2-methylindole-3-carboxylic acid acts as an antagonist of $G$ proteinindependent $\beta$-arrestin coupling promoted by prostaglandin $\mathrm{D} 2$, but has no effect on $\mathrm{G}$ protein-mediated signalling ${ }^{80}$.

FIGURE 8b summarizes the effects of the allosteric modulator LY2033298 on the ability of several orthosteric agonists to mediate the binding of [ ${ }^{35}$ S]GTP $\gamma S$ to activated $\mathrm{G}$ proteins or the phosphorylation of ERK1 or ERK2 via the $\mathrm{M}_{2}$ receptor. Despite being a partial allosteric agonist when acting on its own at the $M_{2}$ receptor, LY2033298 can dramatically modify the signalling profile of the $M_{2}$ receptor when the receptor is co-bound with an orthosteric agonist such as acetylcholine. For example, although acetylcholine-mediated ERK1 or ERK2 phosphorylation is essentially unaltered, acetylcholine-mediated $\left[{ }^{35} \mathrm{~S}\right] \mathrm{GTP} \gamma \mathrm{S}$ binding is potentiated when LY2033298 is present, and LY2033298 completely abrogates the signalling of the agonist xanomeline at both pathways ${ }^{83}$; the modulator essentially converts xanomeline from an agonist into an antagonist (FIG. 8b).

Findings such as these have substantial implications for modern preclinical drug discovery. In addition to highlighting the need to profile the activity of candidate compounds as broadly as possible, these findings have significance when screening for allosteric modulators: namely, the characteristics of the orthosteric agonist that is used as a reference probe for measuring seven-transmembrane receptor activity and modulation should be carefully considered. Ideally, the endogenous agonist should be used; if a different agonist is used (to the endogenous one), this can result in types of modulation and bias that are not seen with (and thus not predictive of the effects on) the endogenous agonist. If a given receptor has more than one endogenous agonist, then all of these agonists should be tested ${ }^{87}$.

A third and relatively unappreciated consideration is the fact that the signalling produced by metabolites of endogenous agonists may also be prone to allosteric modulation in a manner that is different from the parent molecule. For example, the signalling properties of the metabolic products choline, inosine and GLP1 (glucagon-like peptide 1; residues 9-36) undergo substantial allosteric modulation by chemically distinct allosteric ligands of the $M_{2}, A_{1}$ adenosine and GLP1 receptor, respectively ${ }^{88}$. This finding highlights that the bias induced by several endogenous agonists and their metabolic products has an impact on both physiology and in disease, and must therefore be considered when assessing biased signalling.

\section{Therapeutic implications}

Although several biased agonists have been described from in vitro profiles in the literature, the therapeutic impact of this phenomenon in vivo is still not clear. Some predictions have been made suggesting that the pharmacological activation of some but not all - of the signalling produced by agonists is beneficial to the host organ. For example, although opioids are useful analgesics, they can also produce respiratory depression - an effect that is linked to the activation of $\beta$-arrestin ${ }^{7}$. Therefore, an 
opioid agonist that stimulates opioid analgesia pathways without promoting receptor$\beta$-arrestin interactions would be predicted to have fewer side effects ${ }^{8-10}$.

It should also be noted that the occupancy of receptors by biased ligands may preclude receptor occupancy by the endogenous agonists, and this may be an important feature of the therapeutic profile of biased ligands. For example, blockade of angiotensin receptors with standard angiotensinblocking drugs such as losartan precludes the damaging angiotensin-mediated vasoconstriction in heart failure. In vivo treatment with a biased angiotensin ligand such as TRV120027 (Sar-Arg-Val-Tyr-Ile-HisPro-D-Ala-OH) blocks angiotensin but also promotes the beneficial effects of $\beta$-arrestin activation (via stimulation of p42 and/or p44 MAPK, SRC and endothelial nitric oxide synthase phosphorylation) and is thus predicted to have a therapeutic advantage ${ }^{89-93}$.

In vivo data to support this come from studies using rats in which blockade of endogenous angiotensin with the conventional angiotensin receptor antagonists losartan or telmisartan led to reduced mean arterial pressure as well as a decrease in cardiac performance. However, rather than decreasing cardiac performance, treatment with the biased ligand TRV120027 increases cardiac performance and preserves cardiac stroke volume ${ }^{94}$. A similar effect is seen in canine models of heart failure in which TRV120027 produces cardiac unloading actions but preserves renal function ${ }^{95,96}$.

At present, biased signalling is proposed to be useful in several diseases, including heart failure ( $\beta$-adrenergic receptors $)^{97-99}$, hyperlipidaemia (nicotinic acid receptors) ${ }^{100,101}$, hypertension ( $\alpha_{2}$-adrenergic receptors $)^{102}$, some neuropsychiatric and/or neurodegenerative disorders (histamine $\mathrm{H}_{1}$ receptors) ${ }^{103}$, hypothyroidism (thyroid-stimulating hormone receptor) ${ }^{104}$, small-cell lung cancer (gastrin-releasing peptide (GRP) and vasopressin receptors) ${ }^{68}$, schizophrenia (dopamine $\mathrm{D}_{2}$ receptors) ${ }^{105-107}$, osteoporosis (PTH receptors) ${ }^{67,108,109}$, Parkinson's disease (dopamine $\mathrm{D}_{1}$ receptors $)^{110}$, diabetes (GLP1 receptors $)^{69}$, as well as addiction, psychosis and depression (5-hydroxytryptamine (5-HT; serotonin) receptors $)^{111-113}$.

It should also be noted, however, that there is no a priori reason to expect ligand bias to be associated only with improved therapeutic outcomes. It is possible that biased signalling may also be associated with undesirable side effects and even contribute to disease. Recent findings provide support for the possibility that biased signalling could have detrimental effects. For example, the bacterium Neisseria meningitidis possesses filamentous structures known as pili and these have been shown to interact in a biased and allosteric manner with the $\beta_{2}$-adrenergic receptor to initiate signalling cascades that facilitate meningeal colonization ${ }^{114}$.

\section{Conclusions}

The ability of seven-transmembrane receptors to form different ligand-induced conformations necessitates a specific analysis of the consequences of ligand-induced activation of these receptors, either in the form of the direct signalling induced or via the changes induced in the direct signalling of their endogenous agonists. In our view, the data to date that we have highlighted above indicate that the most reliable methods for characterizing the ability of new ligands to produce these effects include the quantification of ligand bias ratios determined from transduction coefficients $\left(\Delta \Delta \log \left(\tau / \mathrm{K}_{\mathrm{A}}\right)\right)$ and/or in some cases relative activity values $(\Delta \Delta \log (\mathrm{RA}))$.

At present, however, these tools only allow the characterization of molecules that then need to be tested in vivo to further assess the impact of biased signalling on therapeutic responses. The therapeutic promise of biased signalling augurs that a wave of biased ligands are poised to enter the clinic. At present, the most advanced molecule is the biased angiotensin ligand TRV120027 (REFS 95,96). It will be interesting to see the therapeutic phenotypic profile of this and other biased molecules in future drug therapy.

Terry Kenakin is at the Department of Pharmacology, University of North Carolina School of Medicine 120 Mason Farm Road, Room 4042, Genetic Medicine Building, CB 7365, Chapel Hill, North Carolina 27599-7365, USA.

Arthur Christopoulos is in the Drug Discovery Biology Theme and at the Department of Pharmacology, Monash Institute of Pharmaceutical Sciences, Monash University, 381 Royal Parade, Parkville, Victoria 3052, Australia.

Correspondence to T.K e-mail:kenakin@email.unc.edu doi: $10.1038 /$ nrd3954 Published online 15 February 2013

Stephenson, R. P. A modification of receptor theory. Br. J. Pharmacol. 11, 379-393 (1956).

2. Kenakin, T. P. Agonist-receptor efficacy II: agonist-trafficking of receptor signals. Trends Pharmacol. Sci. 16, 232-238 (1995).

3. Kenakin, T. P. Perspectives in pharmacology: functional selectivity and biased receptor signaling. J. Pharmacol. Exp. Ther. 336, 296-302 (2010).

4. Perez, D. M. \& Karnick, S. S. Multiple signaling states of G-protein coupled receptors. Pharmacol. Rev. 57 , 147-161 (2005).

5. Kenakin, T. P. \& Miller, L. J. Seven transmembrane receptors as shapeshifting proteins: the impact of allosteric modulation and functional selectivity on new drug discovery. Pharmacol. Rev. 62, 265-304 (2010).
6. Hermans, E. Biochemical and pharmacological control of the multiplicity of coupling at G-protein coupled receptors. Pharmacol. Ther. 99, 25-44 (2003).

Raehal, K. M., Walker, J. K. L. \& Bohn, L. M. Morphine side effects in $\beta$-arrestin 2 knockout mice. J. Pharmacol. Exp. Ther. 314, 1195-1201 (2005).

8. Bohn, L.et al. Enhanced morphine analgesia in mice lacking $\beta$-arrestin 2. Science 286, 2495-2498 (1999).

. Xu, H. et al. A comparison of noninternalizing (herkinorin) and internalizing (DAMGO) $\mu$-opioid agonists on cellular markers related to opioid tolerance and dependence. Synapse 61, 166-175 (2007).

10. Groer, C. E. et al. An opioid agonist that does not induce mu opioid receptor-arrestin interactions or receptor internalization. Mol. Pharmacol. 71 549-557 (2007).

11. Roth, B. L. $\&$ Chuang, D.-M. Multiple mechanisms of serotonergic signal transduction. Life Sci. 41, 1051-1064 (1987).

12. Spengler, D. et al. Differential signal transduction by five splice variants of the PACAP receptor. Nature 365, 170-175 (1993)

13. Mottola, D. M. et al. Dihydrexidine, a selective dopamine receptor agonist that may discriminate postsynaptic D2 receptors. Soc. Neurosci. Abstr. 17, 818 (1991)

14. Roerig, S. C., Loh, H. H. \& Law, P. Y. Identification of three separate guanine nucleotide-binding proteins that interact with the $\delta$-opioid receptor in NG108-15X glioma hybrid cells. Mol. Pharmacol. 41, 822-831 (1992).

15. Fisher, A. et al. Selective signaling via unique $M 1$ muscarinic agonists. Ann. NY Acad. Sci. 695 , 300-303 (1993).

16. Gurwitz, D. et al. Discrete activation of transduction pathways associated with acetylcholine $M 1$ receptor by several muscarinic ligands. Eur. J. Pharmacol. 267, 21-31 (1994).

17. Lawler, C. O., Watts, V. J., Booth, R. G. Southerland, S. B. \& Mailman, R. B. Discrete functional selectivity of drugs: OPC-14597, a selective antagonist for post-synaptic dopamine D2 receptors. Soc. Neurosci. Abstr. 20, 525 (1994).

18. Berg, K. A. et al. Effector pathway-dependent relative efficacy at serotonin type $2 \mathrm{~A}$ and $2 \mathrm{C}$ receptors: evidence for agonist-directed trafficking of receptor stimulus. Mol. Pharmacol. 54, 94-104 (1998).

19. Whistler, J. L., Chuang, H. H., Chu, P., Jan, L. Y. \& van Zastrow, M. Functional dissociation of $\mu$ opioid receptor signaling and endocytosis: implications for the biology of opiate tolerance and addiction. Neuron 23, 737-746 (1999).

20. Jarpe, M. B. et al. [D-Arg ${ }^{1}, \mathrm{D}-\mathrm{Ph}^{5}, \mathrm{D}-\operatorname{Tr}^{7,9}$, Leu $^{11}$ ] Substance $P$ acts as a biased agonist toward neuropeptide and chemokine receptors. J. Biol. Chem. 273, 3097-3104 (1998).

21. Kudlacek, O. et al. biased inhibition by a suramin analogue of $A_{1}$-adenosine receptor/G protein coupling in fused receptor/G protein tandems: the $A_{1}$ adenosine receptor is predominantly coupled to Goa in human brain. Naunyn Schmiedebergs Arch. Pharmacol. 365, 8-16 (2002).

22. Manning, D. R. Measures of efficacy using G proteins as endpoints: differential engagement of $G$ proteins through single receptors. Mol. Pharmacol. 62, 451-452 (2002).

23. Lawler, C. P. et al. Interactions of the novel antipsychotic aripiprazole (OPC-14597) with dopamine and serotonin receptor subtypes. Neuropsychopharmacology 20, 612-627 (1999)

24. Kilts, J. D et al. Functional selectivity of dopamine receptor agonists: II actions of dihydrexidine in D2L receptor transfected MN9D cells and pituitary lactotrophs. J. Pharmacol. Exp. Ther. 301, 1179-1189 (2002).

25. Shapiro, D. A. et al. Aripiprazole, a novel atypical antipsychotic drug with a unique and robust pharmacology. Neuropsychopharmacology $\mathbf{2 8 ,}$ 1400-1411 (2003)

26. Gregory, K. J., Hall, N. E., Tobin, A. B., Sexton, P. M. \& Christopoulos, C. A. Identification of orthosteric and allosteric site mutations in $\mathrm{M}_{2}$ muscarinic acetylcholine receptors that contribute to ligandselective signaling bias. J. Biol. Chem. 285, 7459-7474 (2010).

27. Kenakin, T. P., Ambrose, J. R. \& Irving, P. E. The relative efficiency of $\beta$-adrenoceptor coupling to myocardial inotropy and diastolic relaxation: organ selective treatment for diastolic dysfunction. J. Pharmacol. Exp. Ther. 257, 1189-1197 (1991) 
28. Galandrin, S. \& Bouvier, M. Distinct signaling profiles of $\beta_{1}$ and $\beta_{2}$ adrenergic receptor ligands toward adenylyl cyclase and mitogen-activated protein kinase reveals the pluridimensionality of efficacy. Mol. Pharmacol. 70, 1575-1158 (2006).

29. Gether, U., Lin, S. \& Kobilka, B. K. Fluorescent labeling of purified $\beta_{2}$-adrenergic receptor: evidence for ligand specific conformational changes. J. Biol. Chem. 270, 28268-28275 (1995).

30. Ghanouni, P. et al. Functionally different agonists produce distinct conformations in G-protein coupling domains of the $\beta_{2}$-adrenergic receptor. J. Biol. Chem. 276, 24433-24436 (2001).

31. Kobilka, B. K. \& Gether, U. Use of fluorescence spectroscopy to study conformational changes in the $\beta$-adrenoceptor. Methods Enzymol. 343, 170-182 (2002)

32. Viladarga, J. P., Steinmeyer, R., Harms, G. S. \& Lohse, M. J. Molecular basis of inverse agonism in a G-protein coupled receptor. Nature Chem. Biol. 1 25-28 (2005).

33. Swaminath, G. et al. Probing the $\beta_{2}$-adrenoceptor binding site with catechol reveals differences in binding and activation by agonists and partial agonists. J. Biol. Chem. 280, 22165-22171 (2005).

34. Granier, S. et al. Structure and conformational changes in the $\mathrm{C}$-terminal domain of the $\beta_{2}$-adrenoceptor: insights from fluorescence resonance energy transfer studies. J. Biol. Chem. 282, 13895-13905 (2007).

35. Lohse, M. J. et al. Kinetics of G-protein-coupled receptor signals in intact cells. Br. J. Pharmacol. 153, S125-S132 (2008).

36. Zurn, A. et al. Fluorescence resonance energy transfer analysis of a $2 \mathrm{a}$-adrenergic receptor activation reveals distinct agonist-specific conformational changes. Mol. Pharmacol. 75, 534-541 (2009).

37. Hruby, V. J. \& Tollin, G. Plasmon-waveguide resonance (PWR) spectroscopy for directly viewing rates of GPCR/G-protein interactions and quantifying affinities. Curr. Opin. Pharmacol. 7, 507-514 (2007).

38. Georgieva, T. et al. Unique agonist-bound cannabinoid CB1 receptor conformations indicate agonist specificity in signaling. Eur. J. Pharmacol. 581, 19-29 (2008)

39. Galandrin, S. et al. Conformational rearrangements and signaling cascades invovled in ligand-based mitogen-activated protein kinase signaling through the $\beta_{1}$-adrenergic recepor. Mol. Pharmacol. 74, 162-172 (2008)

40. Baneres, J.-L. et al. Molecular characterization of a purified 5-HT4 receptor. J. Biol. Chem. 280 20253-20260 (2005)

41. Okada, T. \& Palczewski, K. Crystal structure of rhodopsin: implications for vision and beyond. Curr. Opin. Struc. Biol. 11, 420-426 (2001).

42. Pellissier, L. P. et al. Conformational toggle switches implicated in basal constitutive and agonist-induced activated states of 5-hysdroxytryptamine-4 receptors. Mol. Pharmacol. 75, 982-990 (2009).

43. Liu, J. J., Horst, R., Katritch, V., Stevens, R. C. $\&$ Wuthrich, K. Biased-signaling pathways in $\beta_{2}$-adrenergic receptor characterized by ${ }^{19} \mathrm{~F}-\mathrm{NMR}$. Science 335, 1106-1110 (2012).

44. Black, J. W. \& Leff, P. Operational models of pharmacological agonist. Proc. R. Soc. Lond. B Biol. Sci. 220, 141-162 (1983).

45. Kenakin, T. P., Watson, C., Muniz-Medina, V., Christopoulos, A. \& Novick, S. A simple method for quantifying functional selectivity and agonist bias. ACS Chem. Neurosci. 3, 193-203 (2012).

46. Colquhoun, D. Imprecision in presentation of binding studies. Trends Pharmacol. Sci. 6, 197 (1985).

47. Colquhoun, D. Validity of the operational mode Trends Pharmacol. Sci. 10, 17 (1989).

48. Strachan, R. T. et al. Genetic deletion of $\mathrm{p} 90$ ribosomal kinase 2 alters patterns of 5-hydroxytryptamine ${ }_{2 \mathrm{~A}}$ serotonin receptor functional selectivity. Mol. Pharmacol. 77, 327-338 (2010)

49. McPherson, J. et al. $\mu$-opioid receptors: correlation of agonist efficacy for signalling with ability to achieve internalization. Mol. Pharmacol. 78, 756-766 (2010).

50. Nijmeijer, S. et al. Analysis of multiple histamine $\mathrm{H}_{4}$ receptor compound classes uncovers Gai protein- and $\beta$-arrestin2-biased ligands. Mol. Pharmacol. 82 1174-1182 (2012)

51. Onaran, H. O. \& Costa, T. Where have all the active receptor states gone? Nature Chem. Biol. 8, 674-677 (2012)

52. Rasmussen, S. G. F. et al. Crystal structure of the $\beta_{2}$ adrenergic receptor-Gs protein complex. Nature 477, 549-555 (2011).
3. Rasmussen, S. G. F. et al. Structure of a nanobodystabilized active state of the $\beta_{2}$ adrenoceptor. Nature 469, 175-180 (2011)

54. Ehlert, F. J. Analysis of allosterism in functional assays. J. Pharmacol. Exp. Ther. 315, 740-754 (2005).

55. Tran, J. A., Chang, A., Matsui, M. \& Ehlert, F. J. Estimation of relative microscopic affinity constants of agonists for the active state of the receptor in functional studies on $\mu_{2}$ and $\mu_{3}$ muscarinic receptors. Mol. Pharmacol. 75, 381-396 (2009).

56. Figueroa, K. W., Griffin, M. T. \& Ehlert, F. J. Selectivity of agonists for the active state of $\mathrm{M}_{1}$ to $\mathrm{M}_{4}$ muscarinic receptor subtypes. J. Pharmacol. Exp. Ther. 328 331-342 (2009)

57. Black, J. W., Leff, P. \& Shankley, N. P. An operational model of pharmacological agonism: the effect of $E /[A]$ curve shape on agonist dissociation constant estimation. Br. J. Pharmacol. 84, 561-571 (1985).

58. Ehlert, F. J. On the analysis of ligand-directed signalling at $\mathrm{G}$ protein-coupled receptors. Naunyn-Schmiedebergs. Arch. Pharmacol. 377 549-577 (2008).

59. Barlow, R. B., Scott, K. A. \& Stephenson, R. P. An attempt to study the effects of chemical structure on the affintiy and efficacy of compounds related to acetylcholine. Br. J. Pharmacol. 21, 509-522 (1967).

60. Waud, D. R. On the measurement of the affinity of partial aognists for receptors. J. Pharmacol. Exp. Ther 170, 117-122 (1969).

61. Rajagopal, K. et al. Quantifying ligand bias at seven transmembrane receptors. Mol. Pharmacol. $\mathbf{8 0}$ 367-377 (2011).

62. Sato, M., Horinouchi, T., Hutchinson, D. A., Evans, B. A. $\&$ Evans, R. J. Ligand-directed signaling at the $\beta_{3}$-adrenoceptor produced by 3-(2-ethylphenoxy)-1[(1,S)-1,2,3,4-tetrahydronapth-1-ylamino]-2S-2propanol oxalate (SR59230A) relative to receptor agonists. Mol. Pharmacol. 72, 1359-1368 (2007).

63. Barak, L. S. \& Peterson, S. Modeling of bias for the analysis of receptor signaling in biochemical systems. Biochemistry 51, 1114-1125 (2012).

64. Christmanson, L., Westermark, P. \& Betsholtz, C. Islet amyloid polypeptide stimulates cyclic AMP accumulation via the porcine calcitonin receptor. Biochem. Biophys. Res. Commun. 205, 1226-1235 (1994).

65. Watson, C. et al. The use of stimulus-biased assay systems to detect agonist-specific receptor active states: implications for the trafficking of receptor stimulus by agonists. Mol. Pharmacol. 58, 1230-1238 (2000).

66. Peters, M. F. et al. Evaluation of cellular dielectric spectroscopy, a whole-cell, label-free technology for drug discovery on G-coupled GPCRs. J. Biomol. Screen 12, 312-319 (2007)

67. Gesty-Palmer, D. et al. Distinct $\beta$-arrestin- and $G$ protein-dependent pathways for parathyroid hormone receptor-stimulated ERK $1 / 2$ activation. J. Biol. Chem. 281, 10856-10864 (2006).

68. MacKinnon, A. C. et al. Expression of $\mathrm{V}_{1 \mathrm{~A}}$ and $\mathrm{GRP}$ receptors leads to cellular transformation and increased sensitivity to substance-P analogueinduced growth inhibition. Br. J. Cancer 92, 522-531 (2005)

69. Sonoda, N. et al. $\beta$-arrestin-1 mediates glucagon-like peptide-1 signaling to insulin secretion in cultured pancreatic $\beta$ cells. Proc. Natl Acad. Sci. USA 105 , 6614-6619 (2008).

70. Kenakin, T. P. Biased signaling and allosteric machines: new vistas and challenges for drug discovery. Br. J. Pharmacol. 165, 1659-1669 (2012)

71. Christopoulos, A. \& Kenakin, T. P. G-protein coupled receptor allosterism and complexing. Pharmacol. Rev. 54, 323-374 (2002).

72. Christopoulos, A. Allosteric binding sites on cellsurface receptors: novel targets for drug discovery. Nature Rev. Drug Discov. 1, 198-210 (2002).

73. Keov, P., Sexton, P. M. \& Christopoulos, A. Allosteric modulation of $\mathrm{G}$ protein-coupled receptors a pharmacological perspective. Neuropharmacol. 60 , 24-35 (2011)

74. May, L. T., Leach, K., Sexton, P. M. \& Christopoulos, A Allosteric modulation of $\mathrm{G}$ protein-coupled receptors. Annu. Rev. Pharmacol. Toxicol. 47, 1-51 (2007).

75. Kenakin, T. P. New concepts in drug discovery: collateral efficacy and permissive antagonism Nature Rev. Drug Discov. 4, 919-927 (2005)

76. Leach, K., Sexton, P. M. \& Christopoulos, A. Allosteric GPCR modulators: taking advantage of permissive receptor pharmacology. Trends Pharmacol. Sci. 28 382-389 (2007).
Tateyama, M. $\&$ Kubo, Y. Dual signaling is differentially activated by different active states of the metabotropic glutamate receptor 1a. Proc. Natl Acad. Sci. USA 103, 1124-1128 (2006)

78. Sachpatzidis, A. et al. Identification of allosteric peptide agonists of CXCR4. J. Biol. Chem. 278, 896-907 (2003).

79. Valant, C. et al. Synthesis and characterization of novel 2-amino-3-benzoylthiophene derivatives as biased allosteric agonists and modulators of the adenosine $A_{1}$ receptor. J. Med. Chem. 55, 2367-2375 (2012).

80. Mathiesen, J. M. et al. Identification of indole derivatives exclusively interfering with a $\mathrm{G}$ proteinindependent signaling pathway of the prostaglandin D2 receptor CRTH2. Mol. Pharmacol. 68, 393-402 (2005).

81. Zhang, Y., Rodriguez, A. L. \& Conn, P. J. Allosteric potentiators of metabotropic glutamate receptor subtype 5 have differential effects on different signaling pathways in cortical astrocytes. J. Pharmacol. Exp. Ther. 315, 1212-1219 (2005).

82. Maillet, E. L. et al. A novel, conformation-specific allosteric inhibitor of the tachykinin NK2 receptor (NK2R) with functionally selective properties. FASEB J. 21, 2124-2134 (2007).

83. Marlo, J. E. et al. Discovery and characterization of novel allosteric potentiators of $\mathrm{M}_{1}$ muscarinic receptors reveals multiple modes of activity. Mol. Pharmacol. 75, 577-588 (2009).

84. Stewart, G. D., Sexton, P. M. \& Christopoulos, A. Prediction of functionally selective allosteric interactions at an $\mathrm{M}_{3}$ muscarinic acetylcholine receptor mutant using Saccharomyces cerevisiae. Mol. Pharmacol. 78, 205-214 (2010).

85. Goupil, E. et al. A novel biased allosteric compound inhibitor of parturition selectively impedes the prostaglandin F2 $\alpha$-mediated Rho/ROCK signaling pathway. J. Biol. Chem. 285, 25624-25636 (2010)

86. Davey, A. E. et al. Positive and negative allosteric modulators promote biased signaling at the calciumsensing receptor. Endocrinology 153, 1232-1241 (2012).

87. Koole, C. et al. Allosteric ligands of the glucagon-like peptide 1 receptor (GLP-1R) differentially modulate endogenous and exogenous peptide responses in a pathway-selective manner: implications for drug screening. Mol. Pharmacol. 78, 456-465 (2010)

88. Wootten, D. et al. Allosteric modulation of endogenous metabolites as an avenue for drug discovery. Mol. Pharmacol. 82, 281-290 (2012).

89. Rajagopal, K. et al. $\beta$-arrestin-2 mediated inotropic effects of the angiotensin II type $1 \mathrm{~A}$ receptor in isolated cardiac myocytes. Proc. Natl Acad. Sci. USA 103, 16284-16289 (2006).

90. Wei, H. et al. Independent $\beta$-arrestin 2 and $G$ protein mediated pathways for angiotensin II activation of extracellular signal-regulated kinases 1 and 2. Proc. Natl Acad. Sci. USA 100, 10782-10787 (2003).

91. Aplin, M., Bonde, M. M. \& Hansen, J. L. Molecular determinants of angiotensin II type 1 receptor functional selectivity. J. Mol. Cell. Cardiol. 46, 15-24 (2009)

92. Violin, J. D. \& Lefkowitz, R. J. $\beta$-arrestin-biased ligands at seven transmembrane receptors. Trends Pharmacol. Sci. 28, 416-422 (2007)

93. Zhai, P. et al. Cardiac-specific overexpression of At receptor mutant lacking Gaq/Gai coupling causes hypertrophy and bradycardia in transgenic mice. J. Clin. Invest. 115, 3045-3056 (2005).

94. Violin, J. D. et al. Selectively engaging $\beta$-arrestins at the angiotensin II type 1 receptor reduces blood pressure and increases cardiac performance. J. Pharmacol. Exp. Ther. 335, 572-579 (2010).

95. Boerrigter, G. et al. Cardiorenal actions of TRV1 20027, a novel $\beta$-arrestin-biased ligand at the angiotensin II type 1 receptor, in healthy and heart failure canines: a novel therapeutic strategy for acute heart failure. Circ. Heart Fail. 4, 770-778 (2011).

96. Boerrigter, G. et al. TRV 120027 , a novel $\beta$-arrestin biased ligand at the angiotensin II type I receptor, unloads the heart and maintains renal function when added to furosemide in experimental heart failure. Circ. Heart Fail. 5, 627-634 (2012)

97. Shizukuda, Y. \& Buttrick, P. M. Subtype specific role of $\beta$-adrenergic receptors in apoptosis of adult rat ventricular myocytes. J. Mol. Cell. Cardiol. 34 823-831 (2002)

98. Metra, M., Dei Cas, L., di Lenarda, A. \& Poole-Wilson, P. $\beta$-blockers in heart failure: are pharmacological differences clinically important? Heart Fail. Rev. 9, 123-130 (2004). 
99. Wisler, J. W. et al. A unique mechanism of $\beta$-blocker action: carvedilol stimulates $\beta$-arrestin signaling. Proc. Natl Acad Sci. USA 104, 16657-16662 (2007).

100. Walters, R. W. et al. $\beta$-arrestin 1 mediates nicotinic acid-induced flushing, but not its antilipolytic effect, in mice. J. Clin. Invest. 119, 1312-1321 (2009).

101. Richman, J. G. et. al. Nicotinic acid receptor agonists differentially activate downstream effectors. J. Biol. Chem. 283, 6232-6240 (2008)

102. Cottingham, C., Chen, Y. \& Wang, Q. The antidepressant desipramine is an arrestin-biased ligand at the $\alpha_{2 A}$-adrenergic receptor driving receptor downregulation in vitro and in vivo. J. Biol. Chem. 286, 36063-36075 (2011)

103. Galeotti, N., Malmberg-Aiello, P., Bartolini, A. Schunack, W. \& Ghelardini, C. H,-receptor stimulation induces hyperalgesia through activation of the phospholipase C-PKC pathway. Neuropharmacology 47, 295-303 (2004)

104. Vassart, G. \& Dumont, J. E. The thyrotropin receptor and the regulation of thyrocyte function and growth. Endocr. Rev. 13, 596-611 (1992).

105. Mailman, R. B. GPCR functional selectivity has therapeutic impact. Trends Pharmacol. Sci. 28 390-396 (2007)

106. Grady, M. A., Gasperoni, T. L. \& Kirkpatrick, P. Aripiprazole. Nature Rev. Drug Discov. 2, 427-428 (2003)

107. Urban, J. D., Vargas, G. A., von Zastrow, M. \& Mailman, R. B. Aripirazole has functionally selective action at dopamine $D_{2}$ receptor-mediated signaling pathways. Neuropsychopharmacology 32, 67-77 (2007).

108. Gesty-Palmer, D. et al. A $\beta$-arrestin-biased agonist of the parathyroid hormone receptor (PTH1R) promotes bone formation independent of $\mathrm{G}$ protein activation. Sci. Transl. Med. 1, 1ra1 (2009).

109. Ferrari, S. L. et al. Bone response to intermittent parathyroid hormone is altered in mice bull for $\beta$-arrestin2. Endocrinology 146, 1854-1862 (2005).

110. Ryman-Rasmussen, J. P. et al. Functional selectivity of dopamine $D$, receptor agonists in regulating the fate of internalized receptors. Neuropharmacology 52 562-575 (2007)
111. Ji, S.-P. et al. Disruption of PTEN coupling with 5-HT receptors supporesses behavioral responses induced by drugs of abuse. Nature Med. 12, 324-329 (2006)

112. Willins, D. L. et al. Clozapine and other 5-hydroxytryptamine- $2 \mathrm{~A}$ receptor antagonists alter the subcellular distribution of 5-hydroxytryptamine-2A receptors in vitro and in vivo. Neuroscience 91 599-606 (1999)

113. Schmid, C. L., Raehal, K. M. \& Bohn, L. M. Agonist-directed signaling of the serotonin $2 \mathrm{~A}$ receptor depends on $\beta$-arrestin-2 interactions in vivo. Proc. Natl Acad. Sci. USA 105, 1079-1084 (2008).

114. Coureuil, M. et al. Meningococcus hijacks a $\beta 2$-adrenoceptor/ $\beta$-arrestin pathway to cross brain microvasculature endothelium. Cell 143, 1149-1160 (2010).

115. Valant, C., Felder, C. C., Sexton, P. M. \& Christopoulos, A. Probe dependence in the allosteric modulation of a $\mathrm{G}$ protein-coupled receptor: mplications for detection and validation of allosteric ligand effects. Mol. Pharmacol. 81, 41-52 (2012).

\section{Acknowledgements}

Work in A.C.'s laboratory is supported by the Program Grant No. 519461 and Project Grant No. APP1026962 of the National Health and Medical Research Council (NHMRC) of Australia, and Discovery Grant No. DP110100687 of the Australian Research Council. A.C. is an NHMRC Principal Research Fellow.

\section{Competing interests statement}

The authors declare competing financial interests: see Web version for details.

\section{FURTHER INFORMATION}

Author's homepage: http://www.pharm.monash.edu.au/ research/mips/ddb/index.html

SUPPLEMENTARY INFORMATION

See online article: $\underline{\underline{S 1}}$ (box) $\mid \underline{\underline{S 2}}$ (box) $\mid \underline{\mathrm{S} 3}$ (box) $\mid \underline{\mathrm{S} 4}$ (box) $\mid$

$\underline{\mathrm{S}}$ (box) $\mid \underline{\mathrm{S} 6}$ (box) $\mid \underline{\mathrm{S}}$ (box)

ALL LINKS ARE ACTIVE IN THE ONLINE PDF 